DOI: $10.17223 / 17267080 / 69 / 9$

УДК 316.6

\title{
Е.А. Манакова
}

Алтайский государственный педагогический университет

\section{Опросник переживания одиночества}

Представлены результаты разработки методики диагностики особенностей переживания одиночества. На основе теоретического анализа и обзора предшествуюших исследований было выделено пять типов переживания одиночества, для диагностики которых составлен опросник из 30 утверждений. Результаты конфирматорного факторного анализа полностью подтвердили теоретическую структуру методики (объем выборки $N=572$ ), все шкальи показали отличную надежность по внутренней согласованности (альфа Кронбаха 0,76-0,84). Конвергентная валидность шкал подтверждается высокими коррелящиями со шкалой субъективного ощущения одиночества (r от 0,43 и 0,61 для разных шкал). В пользу конструктной валидности свидетельствует наличие предсказуемых корреляций с субъективным благополучием, безнадежностью, стилями привязанности, сочиофобией. Предложенная методика дает возможность измерения новых, прежде не рассмотренных, но представляющии существенный интерес аспектов переживания одиночества.

Ключевые слова: переживание одиночества; сочиофобия; стили привязанности; субъективное благополучие.

\section{Теоретические основы исследования}

Одиночество стало одной из наиболее актуальных проблем современного общества. По данным, предоставленным Всероссийским центром изучения общественного мнения (ВЦИОМ) в последние годы идет увеличение количества одиноких людей в месте своего проживания. Доля таких респондентов наиболее высока среди 18-24-летних (90\%). Одиночество ощущают $13 \%$ россиян, в первую очередь женщины (16\%) [1]. Стоит отметить, что юношеское одиночество приобретает массовый характер. Это обусловлено в первую очередь тем, что именно в данный период возрастает потребность в сотрудничестве с людьми, становится актуальным поиск спутника жизни, появляется чувство интимности с определенными людьми и укрепляются связи со своей социальной группой. Так, по мнению Э. Эриксона, неудовлетворенность такими отношениями или их отсутствие могут усиливать одиночество [2]. И.Н. Ишмухаметов указывает, что переживание одиночества наиболее ярко проявляется в юношеском возрасте вследствие неустойчивого социального положения, индивидуализации деятельности и формализации социальных ролей, тогда как потребность в близких отношениях остается неудовлетворенной [3].

Таким образом, одиночество отражает негативные переживания, связанные с неудовлетворенностью отношениями с окружающими вслед- 
ствие объективного или субъективно воспринимаемого дефицита таких отношений. Переживание одиночества зависит лишь от субъективных представлений о наличии и качестве близких отношений. Это значит, что формальное наличие отношений (например, с супругом / супругой) не свидетельствует об отсутствии переживаний, связанных с одиночеством [4]. Выступая в качестве субъективного состояния, переживание одиночества может быть довольно слабо связано с реальным наличием и качеством отношений.

Вместе с тем необходимо отметить, что стиль привязанности в отношениях влияет на субъективное ощущение одиночества и является одним из факторов его возникновения. В исследованиях детско-родительских отношений было показано, что дети с беспокойной привязанностью более склонны к одиночеству, чем дети с избегающей привязанностью, ввиду того что они более остро переживают неудовлетворенную потребность в любви и защищенности [5]. Для детей с избегающей привязанностью свойственно отрицать или подавлять свою потребность в любви, что приводит к меньшей осознанности и выраженности переживаний, связанных с одиночеством. Неудивительно, что подобные отношения между особенностями привязанности и одиночеством сохраняются и в более позднем возрасте. Целый ряд исследований, проведенных на молодых мужчинах и женщинах, состоящих в супружеских или добрачных отношениях, приводит к выводу о том, что и беспокойный, и избегающий стили привязанности довольно тесно связаны с субъективным ощущением одиночества (см. обзор в [4]). В исследовании на супружеских парах было показано, что лица с ненадежной привязанностью ниже оценивают качество своих отношений и выше - свой уровень одиночества [6]. Т.Л. Крюкова отмечает, что при деструктивной привязанности к партнеру (ненадежный тип привязанности, сопровождающийся высоким уровнем стресса, «срастанием» с партнером, страхом его потерять, ревностью и высокой тревожностью) страдание от одиночества и его переоценка в отношениях возрастают. Автор указывает, что мужчины, находящиеся в браке, со временем чаще признают свое одиночество, принимая его как неизбежность, а женщины чаще, чем мужчины, делают акцент на негативные аспекты переживания в связи с высокими ожиданиями от межличностных отношений и потребностью в выражении чувств [7].

Еще одной не менее важной составляющей эмоциональной стороны переживания одиночества является субъективное благополучие. Д. Касиоппо и соавт. в лонгитюдных исследованиях выявили взаимосвязь переживания одиночества и субъективного благополучия [8]. Учеными было показано, что субъективно оцениваемое одиночество - это более важный предиктор негативных последствий для здоровья, чем реальная (объективная) социальная изоляция. Значимость близких отношений в любом возрасте определяется их влиянием на эмоциональное благополучие и психологический комфорт личности [9], удовлетворением базовой потребности в привязанности и интимности в отношениях [10], возможностью тесного и 
доверительного общения. Е.Н. Осин и Д.А. Леонтьев также отмечают в своем исследовании высокие показатели переживания одиночества у лиц с низким уровнем субъективного благополучия, при актуальном кризисе утраты смысла [11]. Утрата смысла и чувство безнадежности приводят к плохому самочувствию, суицидальному поведению, зависимости и др. Так, Л. Андерсон [12], Д. Перлман и Д. Рассел [13], П. Тиккайнен [14] описывали связь между переживанием одиночества и самоубийством или попыткой самоубийства.

Любопытные данные были получены И.М. Слободчиковым в исследовании субъективного восприятия переживания одиночества у лиц разных возрастных категорий, в том числе периода юности. Автором представлен синонимический ряд понятия «одиночество». В него вошли понятия фобического травматического характера - безнадежность, беспомощность, беззащитность, страх и т.п. [15]. Я. Купершмидт, К. Сигда, М. Веглер и К. Седикидес также указывали, что одинокий человек испытывает эмоциональные проблемы, среди которых социальная тревожность, низкое чувство собственного достоинства, а также застенчивость и обособленность, уменьшение контактов с окружающими [16]. Анализ вышеописанных факторов, являющихся тенденциями возникновения переживания одиночества (субъективное благополучие, стиль привязанности, безнадежность, социальная тревога), показал, что они недостаточно раскрыты в контексте различных типов одиночества, особенно в период юности. Исследования переживания одиночества в возрастной психологии относятся к подростковому, зрелому или пожилому возрасту.

Методологическое значение теорий переживания одиночества (теория одиночества Д. Рассела и Л. Пепло, теоретико-клинический подход А. Бека и др.) и современных исследований заключается в том, что на основе их анализа стало возможным дефинирование одиночества в его субъективном аспекте, а также определение собственных позиций относительно данного переживания. Основываясь на базовых психологических концепциях, рассматривающих одиночество как состояние непатологическое, было разработано обобщающее определение одиночества в контексте уровня удовлетворенности социальных потребностей личности. Одиночество - это негативное социально-психологическое переживание, возникающее в результате неадекватного удовлетворения социальных потребностей личности, следствием которого является ощущение себя как покинутого, ненужного; при этом происходит утрата эмоциональной связи с окружающими. Использование термина «переживание» относительно одиночества связано с определением его в рамках теории переживания Ф.Е. Василюка, который описывал данный процесс как внутренний, сложный, многоэтапный и ведущий к трансформации внутреннего мира, осознаваемая составляющая чувства [17].

Основой для разработки многомерного опросника переживания одиночества послужили результаты проведенного ранее анализа содержания различных подходов и методик диагностики одиночества [18]. С помощью 
кластерного анализа было показано, что содержание большинства популярных в нашей стране опросников для измерения одиночества при обобщении образует следующие категории: переживание одиночества как негативного чувства, отрицание переживания одиночества как негативного чувства и переживание одиночества как временного вынужденного явления. На основе полученной структуры и теоретического анализа данной проблемы переживания были выделены дополнительно три типа переживания одиночества в юношеском возрасте: одиночество как результат страха брать ответственность за других; духовное одиночество как отсутствие поддержки, понимания; одиночество вследствие внешней непривлекательности.

Основываясь на результатах диссертационного исследования [18], можно предположить, что людям, переживающим одиночество как негативное чувство, свойственны тревожность, мнительность и неуверенность в себе. Часто они ощущают беспомощность, некомпетентность и слабость. У них наблюдается низкая терпимость к отрицательным переживаниям и повышенная чувствительность к отвержению или неудаче. Типичной для таких людей эмоцией является дисфория (сочетание тревоги с печалью). Тревогу, как правило, порождает страх стать объектом критики, а также вероятность разрыва зависимых отношений, а печаль - отсутствие близких отношений и успехов. Для них характерны некая интровертированность и осознание проблем через пессимистическую призму оценки своих перспектив. Таким образом, идет преуменьшение значения позитивных или вселяющих оптимизм аспектов. Обычно у таких людей завышенные ожидания в широком спектре ситуаций: что дела в конце концов пойдут плохо или же успехи непременно обернутся неудачами. Как правило, имеет место страх допустить ошибку, которая приведет к унижению или попаданию в проблемную ситуацию. В связи с преувеличением вероятности возможных негативных исходов эти люди часто склонны к беспокойству, бдительности, жалобам и нерешительности. В социальных группах они стараются держаться особняком, основная травма или угроза связана с отказом и отвержением в связи с внутренним специфическим мотивационным конфликтом между напряженным желанием вступить в контакт и субъективно непреодолимым чрезмерным страхом этого контакта. Е.Н. Осин и Д.А. Леонтьев отмечают, что страх отвержения обнаруживает выраженную положительную корреляцию с зависимостью от общения [11].

Людям, отрицающим переживание одиночества как негативное чувство, свойственна определенная автономность, другие люди, как правило, не вызывают у них интереса. Они не допускают близости, стремясь защитить личную независимость и уединенность, относя себя к самодостаточным одиночкам. Ими высоко оцениваются такие качества личности как мобильность и независимость; в приоритете - самостоятельное принятие любого рода решений и действия в одиночку. Они считают навязчивыми других людей и полагают, что близость ущемляет их независимость. Их важнейшая межличностная тактика поведения заключается в том, чтобы 
держаться от других людей настолько далеко, насколько это возможно. Любые попытки сближения с ними воспринимаются как вторжение или угроза. Если люди с данным типом переживания оказываются вынужденными вступить в тесный контакт, то это вызывает у них чувство беспокойства. Им не свойственно выражение чувств мимикой или словами. Вследствие этого может создаться впечатление, что у них отсутствуют сильные чувства. Социальная самоизоляция обычно определяется особой личной философией, а иногда убеждениями во враждебности окружения. Их убеждения носят очень ригидный характер, они не способны сами изменить мнение, даже при объективной необходимости.

Люди с переживанием одиночества как временного вынужденного явления склонны снимать с себя личную ответственность, так как они убеждены, что если что-либо не получается, то не стоит проявлять упорство, хотя и очень хочется, поскольку бывают ситуации, когда нужно подождать более благоприятного стечения обстоятельств без потерь и разочарований. В период вынужденного одиночества происходит максимальная концентрация на себе, возникает озабоченность своим душевным состоянием, что нарушает эмоциональное благополучие. Переосмысление собственного образа объясняет наличие у таких людей убеждения, что в период вынужденного одиночества человек обязательно почувствует вину (стыд, сожаление) за боль, причиненную другому, за свои дурные привычки, за недостаток общей культуры.

Одиночество как результат страха брать ответственность за других является достаточно распространенным типом переживания как среди молодых женщин, так и среди мужчин. Как правило, эти люди не создают семьи и ведут одинокий образ жизни, вступая в отношения, которые не влекут за собой никаких обязательств. Им не свойственно занимать активную жизненную позицию, быть на руководящей должности и получать удовольствие от собственных сил и возможностей. Такие люди не готовы справляться с ответственностью, они чувствуют страх и беспомощность от собственной несостоятельности. Ю.М. Черепухин в процессе социальнодемогра-фического анализа переживания одиночества выделил ряд ориентаций переживания одиночества в негативной форме в зависимости от брачных отношений. Автор указал, что большое количество людей остаются холостыми и незамужними. Выбор одинокого образа жизни, возможно, является результатом избегания обязательств и проблем, которые возникают в супружестве, и снятия ответственности за партнера [19].

Духовное одиночество как отсутствие поддержки, понимания часто переживают люди, которые знают или могут то, что непонятно и недоступно большинству, более того, не оценивается и не признается ими. Именно эти обстоятельства вызывают непонимание, неприятие или пренебрежение со стороны окружающих, несовместимость в системе ценностей. Человек, которому важно делиться своим знанием, который уверен в его эффективности, в данной ситуации чувствует себя неоцененным, осмеянным и непонятым. О.М. Красникова отмечает, что очень трудно и страшно 
быть первым, способным, лучшим и единственным в чем-либо, так как высока вероятность быть осужденным и игнорированным своими современниками. Самое страшное, что может случиться с таким человеком, по мнению автора, это отказ от своего призвания. Поскольку призвание является большой ответственностью, человек будет помнить об этом и не сможет себя простить [20].

Одиночество вследствие внешней непривлекательности является очень тяжелым переживанием, особенно в юношеском возрасте. Популярностью у противоположного пола такие юноши и девушки не пользуются, часто влюбляются в совершенно недоступных и безразличных к ним. Далее, как правило, страдают от безответных чувств и смиряются с мыслью, что никогда не будут встречаться с тем человеком, который им нравиться. Данное обстоятельство приводит к ощущению себя «белой вороной», а при внутреннем убеждении в своей непривлекательности становится серьезной психологической проблемой. При работе с такими людьми очень важно выработать у них умение делать и принимать комплименты, подчеркивать привлекательность физических данных и изучать подходы к физической близости.

Вышеописанные категории не являются статистически независимыми, однако их использование для целей многомерной диагностики позволит получить более полную и содержательную характеристику индивидуальных особенностей переживания одиночества в разных его аспектах. В этой связи целью исследования стала разработка и апробация многофакторного опросника переживания одиночества, структура которого отражает рассмотренные аспекты.

\section{Процедура, выборка и методы исследования}

В процессе разработки опросника с учетом результатов проведенных ранее исследований [18] были сформулированы 72 утверждения, отражающих рассмотренные выше типы переживания одиночества. Составленный из этих утверждений опросник в ходе пилотажного исследования был проведен на выборке из 160 студентов. На основе полученных данных был выполнен отбор заданий, направленный на максимизацию внутренней согласованности шкал путем исключения неработающих пунктов. Полученный в результате этой процедуры текст опросника из 30 пунктов использовался далее в ходе данного исследования, направленного на анализ факторной структуры, надежности и валидности методики.

Выборка данного исследования включает 572 испытуемых в возрасте от 16 до 28 лет $(\mathrm{M}=20,58 ; \mathrm{SD}=3,43)$, большинство из которых составили студенты вузов г. Барнаула. Распределение испытуемых по полу и типу отношений, в которых они состояли на момент исследования, приведено в табл. 1.

В ходе анализа валидности опросника использовался комплекс методик психологической диагностики. Для диагностики субъективного ощущения одиночества использовалась шкала UCLA Д. Рассела в адапта- 
ции И.Н. Ишмухаметова [3], состоящая из 20 утверждений (примеры: «Как часто вы чувствуете себя одиноким?», «Как часто вы чувствуете, что есть люди, с которыми вы можете поговорить?»), которые оцениваются по 4балльной шкале. Надежность шкалы в данном исследовании (коэффициент альфа Кронбаха) составила 0,92 .

Т а бли ц а 1

Состав выборки по типу близких отношений и полу

\begin{tabular}{|l|c|c|c|}
\hline \multicolumn{1}{|c|}{ Тип отношений } & Женщины & Мужчины & Всего \\
\hline Нет отношений & $83(33 \%)$ & $127(51 \%)$ & $210(37 \%)$ \\
\hline Свободные отношения & $16(6 \%)$ & $70(28 \%)$ & $86(15 \%)$ \\
\hline Встречаюсь & $74(29 \%)$ & $73(29 \%)$ & $147(26 \%)$ \\
\hline Сожительство & $22(9 \%)$ & $18(7 \%)$ & $40(7 \%)$ \\
\hline Официальный брак & $52(21 \%)$ & $21(8 \%)$ & $73(13 \%)$ \\
\hline Разведен(а) & $4(2 \%)$ & $1(0 \%)$ & $5(1 \%)$ \\
\hline Другое & $0(0 \%)$ & $11(4 \%)$ & $11(2 \%)$ \\
\hline Всего & $251(44 \%)$ & $321(56 \%)$ & 572 \\
\hline
\end{tabular}

Для диагностики субъективного благополучия использовалась методика «Шкалы субъективного благополучия» А. Бадо и Г.А. Мендельсон, адаптация М.В. Соколовой [21]. Шкала состоит из 17 утверждений, согласие с которыми необходимо оценить по семибалльной шкале от «полностью не согласен» до «полностью согласен». Надежность шкалы (альфа Кронбаха) в данном исследовании составила 0,86 . При интерпретации показателей по шкале субъективного благополучия необходимо учитывать, что она является обратной, т.е. высокие показатели говорят о низком благополучии.

Для оценки безнадежности как показателя неблагополучия и суицидального риска использовалась шкала безнадежности Бека [22]. Безнадежность как переживание отчаяния или крайнего пессимизма по поводу будущего, по данным некоторых исследователей, является одним из наиболее точных предикторов риска суицида в долговременной перспективе [23]. Шкала включает 20 вопросов, оценивающих негативные переживания по поводу будущего. В нашем исследовании надежность шкалы безнадежности (альфа Кронбаха) составила 0,87.

Результаты теоретического анализа показали, что среди личностных особенностей, оказывающих существенное негативное влияние на установление близких отношений, важное место занимают стиль привязанности и социальная тревожность. Эти личностные особенности были измерены в нашем исследовании для анализа конструктной валидности предложенной методики. Для диагностики стиля привязанности использовался «Опросник привязанности к близким людям» Н.В. Сабельниковой и Д.В. Каширского [24]. В основу этого опросника были положены методика «Опыт близких отношений» (ECR) К. Бреннана, С. Кларка и Ф. Шейвера и двухфакторная модель привязанности, в рамках которой стиль привязанности определяется сочетанием беспокойства по поводу отношений и избегания отношений привязанности [25]. Опросник состоит из 30 утвержде- 
ний, согласие с каждым из которых необходимо оценить по шкале от 1 до 7. Надежность шкал (альфа Кронбаха) в нашем исследовании составила 0,74 для шкалы избегания и 0,82 для шкалы беспокойства.

Для оценки социальной тревожности как вероятного фактора одиночества использовался опросник социальной тревоги и социофобии О.А. Сагалаковой и Д.В. Труевцева [26]. Этот опросник предназначен для определения уровня социальной тревожности и ее доминирующего типа, а также выраженности отдельных аспектов проявления страха оценивания в разных ситуациях. Методика состоит из 29 пунктов, сформулированных в виде вопросов, на которые требуется ответить по 4-балльной шкале. Данная методика позволяет получить оценку по пяти шкалам, характеризующим отдельные аспекты проявления социальной тревожности, а также интегральный показатель, отражающий ее общий уровень. В рамках данного исследования использовался только общий показатель социальной тревожности и социофобии. Коэффициент надежности для этого показателя (альфа Кронбаха) составил 0,91.

\section{Результаты}

Описательная статистика и надежность опросника. Распределение по всем шкалам существенно отличается от нормального (значения критерия Шапиро-Уилка от 0,69 до 0,94, все значимы при $p<0,001)$. Значения коэффициента асимметрии по всем шкалам является положительным (от 0,68 по шкале 3 до 2,09 по шкале 6), что свидетельствует о преобладании относительно низких значений. Этот факт отражает сравнительную редкость интенсивных переживаний, связанных с одиночеством, особенно переживаний одиночества как следствия внешней непривлекательности (шкала 6).

Оценка надежности шкал с помощью коэффициентов альфа Кронбаха показала, что все шкалы характеризуются высокой внутренней согласованностью (табл. 2).

Т а бл и ц а 2

Описательная статистика, надежность и интеркорреляции шкал опросника переживания одиночества

\begin{tabular}{|l|c|c|c|c|c|c|c|}
\hline Шкалы / показатели & $\begin{array}{c}\text { Шкала } \\
1\end{array}$ & $\begin{array}{c}\text { Шкала } \\
2\end{array}$ & $\begin{array}{c}\text { Шкала } \\
3\end{array}$ & $\begin{array}{c}\text { Шкала } \\
4\end{array}$ & $\begin{array}{c}\text { Шкала } \\
5\end{array}$ & $\begin{array}{c}\text { Шкала } \\
6\end{array}$ & $\begin{array}{c}\text { Общий } \\
\text { показа- } \\
\text { тель }\end{array}$ \\
\hline $\begin{array}{l}\text { Шкала 1. Пережи- } \\
\text { вание одиночества } \\
\text { как негативного } \\
\text { чувства }\end{array}$ & - & & & & & & \\
\hline $\begin{array}{l}\text { Шкала 2. Отрица- } \\
\text { ние переживания } \\
\text { одиночества }\end{array}$ & $0,36 * * *$ & - & & & & & \\
\hline $\begin{array}{l}\text { Шкала 3. Пережи- } \\
\text { вание одиночества } \\
\text { как временного } \\
\text { вынужденного } \\
\text { явления }\end{array}$ & $0,42 * * *$ & $0,68 * * *$ & - & & & & \\
\hline
\end{tabular}




\begin{tabular}{|l|c|c|c|c|c|c|c|}
\hline Шкалы / показатели & $\begin{array}{c}\text { Шкала } \\
1\end{array}$ & $\begin{array}{c}\text { Шкала } \\
2\end{array}$ & $\begin{array}{c}\text { Шкала } \\
3\end{array}$ & $\begin{array}{c}\text { Шкала } \\
4\end{array}$ & $\begin{array}{c}\text { Шкала } \\
5\end{array}$ & $\begin{array}{c}\text { Шкала } \\
6\end{array}$ & $\begin{array}{c}\text { Общий } \\
\text { показа- } \\
\text { тель }\end{array}$ \\
\hline $\begin{array}{l}\text { Шкала 4. Одиноче- } \\
\text { ство как результат } \\
\text { страха брать ответ- } \\
\text { ственность за дру- } \\
\text { гих }\end{array}$ & $0,38^{* * *}$ & $0,70 * * *$ & $0,49 * * *$ & - & & & \\
\hline $\begin{array}{l}\text { Шкала 5. Духовное } \\
\text { одиночество как } \\
\text { отсутствие под- } \\
\text { держки, понимания }\end{array}$ & $0,64 * * *$ & $0,55^{* * *}$ & $0,54 * * *$ & $0,58 * * *$ & - & & \\
\hline $\begin{array}{l}\text { Шкала 6. Одиноче- } \\
\text { ство вследствие } \\
\text { внешней непривле- } \\
\text { кательности }\end{array}$ & $0,50^{* * *}$ & $0,40^{* * *}$ & $0,34 * * *$ & $0,49 * * *$ & $0,60 * * *$ & - & \\
\hline Общий показатель & $0,69 * * *$ & $0,82^{* * *}$ & $0,78^{* * *}$ & $0,79 * * *$ & $0,83^{* * *}$ & $0,69^{* * *}$ & - \\
\hline Среднее & 7,69 & 8,86 & 10,81 & 7,78 & 7,81 & 7,03 & 49,97 \\
\hline $\begin{array}{l}\text { Стандартное откло- } \\
\text { нение }\end{array}$ & 3,31 & 4,05 & 4,41 & 3,62 & 3,50 & 3,09 & 16,98 \\
\hline $\begin{array}{l}\text { Надежность } \\
\text { (Альфа Кронбаха) }\end{array}$ & 0,76 & 0,84 & 0,79 & 0,82 & 0,85 & 0,81 & 0,93 \\
\hline
\end{tabular}

$* * * \mathrm{p}<0,001$.

Факторная структура. На основе теоретической структуры опросника была построена факторная модель, включающая шесть взаимосвязанных факторов, соответствующих шкалам переживания одиночества. Оценка соответствия этой модели полученным данным проводилась с помощью конфирматорного факторного анализа в программе Mplus 7 с использованием алгоритма MLR, позволяющего получить робастные (устойчивые по отношению к отклонению от нормального распределения) оценки. В результате анализа модели были получены показатели, свидетельствующие о хорошем соответствии теоретической модели полученным данным: $\chi^{2}=696,308 ; \mathrm{df}=390 ; \mathrm{p}<0,001 ; \mathrm{CFI}=0,939 ; \mathrm{NNFI}=0,932$; RMSEA $=$ 0,037; доверительный интервал для RMSEA: 0,033-0,041; $\mathrm{N}=572$. В наглядном виде полученная модель отражена на рис. 1.

Для исследования факторной структуры второго уровня был выполнен анализ главных компонент суммарных оценок по шести шкалам. Результаты анализа свидетельствуют в пользу однофакторного решения: собственное число, превышающее единицу, было получено только для первого фактора, при этом факторные нагрузки на общий фактор для всех шкал составляли не менее 0,70 . Это означает, что на верхнем уровне структуры опросника все его шкалы образуют единый фактор переживания одиночества.

Валидность. Для анализа конвергентной валидности методики был проведен корреляционный анализ ее шкал с оценками по шкале субъективного ощущения одиночества Д. Рассела и М. Фергюсона. Приведенные в табл. 3 коэффициенты корреляции свидетельствуют о том, что все опи- 
санные типы переживания одиночества более свойственны лицам, испытывающим сильное субъективное ощущение одиночества. При этом наиболее тесную связь с субъективным ощущением одиночества показывают шкалы «Переживание одиночества как негативного чувства» и «Духовное одиночество как отсутствие поддержки, понимания», а также суммарный показатель.

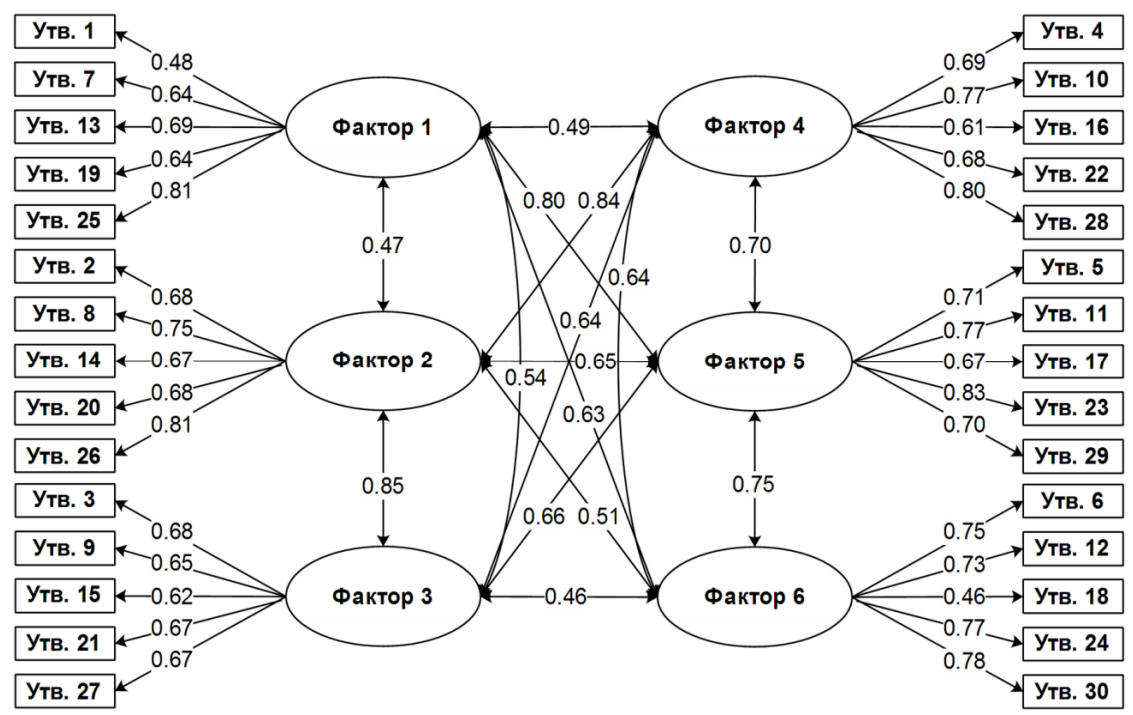

Рис. 1. Факторная модель опросника переживания одиночества.

Все приведенные коэффициенты стандартизованы и статистически значимы при $\mathrm{p}<0,01$ (нумерация факторов соответствует нумерации шкал, названия шкал см. в табл. 2)

Т а бл и ц а 3

Коэффициенты корреляции шкал переживания одиночества с субъєктивным ощущением одиночества по шкале Д. Рассела и М. Фергюсона $(\mathbf{N}=572)$

\begin{tabular}{|l|c|}
\hline \multicolumn{1}{|c|}{ Шкалы переживания одиночества } & $\begin{array}{c}\text { Коэффициент } \\
\text { корреляции }\end{array}$ \\
\hline Шкала 1. Переживание одиночества как негативного чувства & $0,57 * * *$ \\
\hline Шкала 2. Отрицание переживания одиночества & $0,47^{* * *}$ \\
\hline $\begin{array}{l}\text { Шкала 3. Переживание одиночества как временного вынужденного } \\
\text { явления }\end{array}$ & $0,44 * * *$ \\
\hline $\begin{array}{l}\text { Шкала 4. Одиночество как результат страха брать ответственность за } \\
\text { других }\end{array}$ & $0,43 * * *$ \\
\hline Шкала 5. Духовное одиночество как отсутствие поддержки, понимания & $0,61 * * *$ \\
\hline Шкала 6. Одиночество вследствие внешней непривлекательности & $0,42^{* * *}$ \\
\hline Общий показатель & $0,63 * * *$ \\
\hline$* * *$ р $<0,001$. & \\
\hline
\end{tabular}

Анализ конструктной валидности был направлен на проверку гипотез о связи переживания одиночества с другими психическими явлениями, вы- 
ступающими в качестве вероятных причин или последствий переживания одиночества. С учетом результатов теоретического анализа было выдвинуто предположение о связи различных форм переживания одиночества с показателями психологического благополучия личности и личностными особенностями, оказывающими существенное влияние на установление близких отношений. Результаты анализа связи переживания одиночества с показателями психологического благополучия представлены в табл. 4.

Т а б л и ц а 4

Коэффициенты корреляции шкал переживания одиночества со шкалами субъективного благополучия и безнадежности

\begin{tabular}{|l|c|c|}
\hline \multicolumn{1}{|c|}{ Шкалы переживания одиночества } & $\begin{array}{c}\text { Шкала } \\
\text { субъектив- } \\
\text { ного благо- } \\
\text { получия }\end{array}$ & $\begin{array}{c}\text { Шкалала } \\
\text { сти }\end{array}$ \\
\hline Объем выборки N & 572 & 175 \\
\hline $\begin{array}{l}\text { Шкала 1. Переживание одиночества как негативного чув- } \\
\text { ства }\end{array}$ & $0,52 * * *$ & $0,27 * * *$ \\
\hline Шкала 2. Отрицание переживания одиночества & $0,42^{* * *}$ & $0,27 * * *$ \\
\hline $\begin{array}{l}\text { Шкала 3. Переживание одиночества как временного вы- } \\
\text { нужденного явления }\end{array}$ & $0,34^{* * *}$ & $-0,01$ \\
\hline $\begin{array}{l}\text { Шкала 4. Одиночество как результат страха брать ответ- } \\
\text { ственность за других }\end{array}$ & $0,45^{* * *}$ & $0,26^{* * *}$ \\
\hline $\begin{array}{l}\text { Шкала 5. Духовное одиночество как отсутствие поддержки, } \\
\text { понимания }\end{array}$ & $0,57 * * *$ & $0,26 * * *$ \\
\hline $\begin{array}{l}\text { Шкала 6. Одиночество вследствие внешней непривлека- } \\
\text { тельности }\end{array}$ & $0,45^{* * *}$ & $0,25^{* * *}$ \\
\hline Общий показатель & $0,59 * * *$ & $0,26^{* * *}$ \\
\hline
\end{tabular}
$* * * \mathrm{p}<0,001$.

Представленные коэффициенты корреляции свидетельствуют о том, что все типы переживания одиночества, за исключением переживания одиночества как временного вынужденного явления, связаны с безнадежностью, представляющей собой один из наиболее существенных предикторов суицида и важный симптом депрессии [23]. Корреляции с субъективным благополучием также свидетельствуют о том, что переживание одиночества как временного вынужденного явления наносит наименьшей ущерб благополучию и может рассматриваться как наиболее конструктивный вариант. Наибольший ущерб психологическому благополучию наносят духовное одиночество и переживание одиночества как негативного явления.

В соответствии с предположением о связи одиночества с личностными особенностями, затрудняющими установление отношений, также были получены статистически значимые коэффициенты корреляция шкал переживания одиночества с параметрами стиля привязанности и социальной тревожностью (табл. 5). 
Т а б ли и а 5

Коэффициенты корреляции шкал переживания одиночества с параметрами стиля привязанности и социальной тревожностью $(\mathrm{N}=\mathbf{5 7 2})$

\begin{tabular}{|l|c|c|c|}
\hline \multicolumn{1}{|c|}{ Шкалы переживания одиночества } & $\begin{array}{c}\text { Избега- } \\
\text { ние }\end{array}$ & $\begin{array}{c}\text { Беспокой- } \\
\text { ство }\end{array}$ & $\begin{array}{c}\text { Социальная } \\
\text { тревож- } \\
\text { ность }\end{array}$ \\
\hline $\begin{array}{l}\text { Шкала 1. Переживание одиночества как негатив- } \\
\text { ного чувства }\end{array}$ & 0,07 & $0,42 * * *$ & $0,40^{* * *}$ \\
\hline Шкала 2. Отрицание переживания одиночества & $0,15^{* * *}$ & $0,19 * * *$ & $0,36^{* * *}$ \\
\hline $\begin{array}{l}\text { Шкала 3. Переживание одиночества как временно- } \\
\text { го вынужденного явления }\end{array}$ & 0,07 & $0,22^{* * *}$ & $0,28^{* * *}$ \\
\hline $\begin{array}{l}\text { Шкала 4. Одиночество как результат страха брать } \\
\text { ответственность за других }\end{array}$ & $0,25^{* * *}$ & $0,17^{* * *}$ & $0,35^{* * *}$ \\
\hline $\begin{array}{l}\text { Шкала 5. Духовное одиночество как отсутствие } \\
\text { поддержки, понимания }\end{array}$ & $0,18^{* * *}$ & $0,35^{* * *}$ & $0,44^{* * *}$ \\
\hline $\begin{array}{l}\text { Шкала 6. Одиночество вследствие внешней не- } \\
\text { привлекательности }\end{array}$ & $0,21 * * *$ & $0,28^{* * *}$ & $0,39^{* * *}$ \\
\hline Общий показатель & $0,20^{* * *}$ & $0,34 * * *$ & $0,47^{* * *}$ \\
\hline
\end{tabular}
$* * * \mathrm{p}<0,001$.

Полученные результаты свидетельствуют о том, что переживание одиночества как негативного чувства весьма характерно для лиц с высокой выраженностью беспокойства, в то время как избегание не показывает связи с таким типом переживания. Аналогичным образом переживание одиночества как временного вынужденного явления связано с беспокойством, но совершенно не связано с избеганием. Остальные варианты переживания одиночества связаны как с избеганием, так и с беспокойством, однако можно отметить, что одиночество как результат страха брать ответственность за других несколько более свойственно лицам с высоким избеганием в отношениях, в то время как духовное одиночество более свойственно лицам с высоким беспокойством. В целом различные переживания, связанные с одиночеством, более свойственны лицам с высокой выраженностью беспокойства, хотя избегание также показывает умеренную связь.

Выявленные значительные различия в связи параметров привязанности с различными шкалами переживания одиночества представляют особенно большой интерес в связи с тем, что субъективное ощущение одиночества по шкале Д. Рассела и М. Фергюсона одинаково тесно связано как с избеганием $(\mathrm{r}=0,44 ; \mathrm{p}<0,001)$, так и с беспокойством $(\mathrm{r}=0,51 ; \mathrm{p}<0,001)$. Это означает, что лица разными стилями ненадежной привязанности примерно в равной мере страдают от одиночества, однако характер переживаний, связанных с одиночеством, у них существенно различается. Таким образом, ненадежная привязанность действительно оказывает влияние на содержание и выраженность переживаний, связанных с одиночеством.

Социальная тревога и социофобия также могут рассматриваться в качестве существенного фактора переживания одиночества. Полученные в данном исследовании результаты корреляционного анализа, приведенные в табл. 4, свидетельствуют в пользу такого предположения. Социальная 
тревожность тесно связана с общей выраженностью переживания одиночества, а также со всеми типами переживаний. Необходимо отметить, что социальная тревожность в наибольшей мере способствует переживанию духовного одиночества, а также одиночества как негативного чувства.

Связь переживания одиночества с демографическими характеристиками. Результаты анализа зависимости переживания одиночества от пола, приведенные в табл. 6, свидетельствуют о том, что переживание одиночества как следствие страха принятия ответственности в равной мере свойственно как женщинам, так и мужчинам. Однако другие переживания, связанные с одиночеством, в большей мере свойственны женщинам.

Т а бли ца 6

Гендерные различия по шкалам переживания одиночества

\begin{tabular}{|l|c|c|c|c|c|c|c|}
\hline \multicolumn{1}{|c|}{$\begin{array}{c}\text { Шкалы переживания } \\
\text { одиночества }\end{array}$} & \multicolumn{2}{|c|}{$\begin{array}{c}\text { Мужчины } \\
\text { (N=321) }\end{array}$} & \multicolumn{2}{c|}{$\begin{array}{c}\text { Женщины } \\
\text { (N=251) }\end{array}$} & \multirow{2}{*}{$\begin{array}{c}\text { p- } \\
\text { уровень }\end{array}$} & $\begin{array}{c}\text { d- } \\
\text { Коэна }\end{array}$ \\
\cline { 2 - 7 } & $\mathrm{M}$ & $\mathrm{SD}$ & $\mathrm{M}$ & $\mathrm{SD}$ & & & \\
\hline $\begin{array}{l}\text { Шкала 1. Переживание } \\
\text { одиночества как негатив- } \\
\text { ного чувства }\end{array}$ & 6,97 & 2,66 & 8,62 & 3,80 & 6,08 & $<0,001$ & 0,51 \\
\hline $\begin{array}{l}\text { Шкала 2. Отрицание пере- } \\
\text { живания одиночества }\end{array}$ & 8,26 & 3,90 & 9,63 & 4,12 & 4,08 & $<0,001$ & 0,34 \\
\hline $\begin{array}{l}\text { Шкала 3. Переживание } \\
\text { одиночеста как временно- } \\
\text { го вынужденного явления }\end{array}$ & 10,02 & 4,21 & 11,82 & 4,48 & 4,92 & $<0,001$ & 0,41 \\
\hline $\begin{array}{l}\text { Шкала 4. Одиночество как } \\
\text { результат страха брать } \\
\text { ответственность за других }\end{array}$ & 7,69 & 3,58 & 7,89 & 3,67 & 0,67 & $\begin{array}{c}\text { незна- } \\
\text { чим }\end{array}$ & 0,06 \\
\hline $\begin{array}{l}\text { Шкала 5. Духовное одино- } \\
\text { чество как отсутствие под- } \\
\text { держки, понимания }\end{array}$ & 7,36 & 3,25 & 8,37 & 3,73 & 3,46 & $<0,001$ & 0,29 \\
\hline $\begin{array}{l}\text { Шкала 6. Одиночество } \\
\text { вследствие внешней не- } \\
\text { привлекательности }\end{array}$ & 6,79 & 2,88 & 7,33 & 3,33 & 2,09 & $<0,05$ & 0,18 \\
\hline Общий показатель & 47,09 & 16,10 & 53,66 & 17,40 & 4,68 & $<0,001$ & 0,39 \\
\hline
\end{tabular}

Примечание. М - среднее значение; SD - стандартное отклонение; t - значение t-критерия Стьюдента для независимых выборок.

Величина коэффициентов d-Коэна, характеризующих размер эффекта, указывает на то, что довольно сильные гендерные различия обнаруживаются по шкалам «Переживание одиночества как негативного чувства» и «Переживание одиночества как временного вынужденного явления». В сравнении с мужчинами женщины в большей мере склонны интерпретировать одиночество как негативное состояние. С другой стороны, они же более склонны рассматривать одиночество как временное вынужденное явление.

Приведенные в табл. 7 коэффициенты корреляции показателей одиночества с возрастом свидетельствуют о том, что связь переживания одиночества с возрастом зависит от пола. Если у мужчин с возрастом усилива- 
ется как субъективное ощущение одиночества, так и все различные варианты переживания одиночества, то у женщин рост отмечается только по шкале «Переживание одиночества как временного вынужденного явления».

Т а б л и ц а 7

Коэффициенты корреляции показателей переживания одиночества с возрастом

\begin{tabular}{|l|c|c|c|}
\hline \multicolumn{1}{|c|}{ Показатели } & \multicolumn{3}{c|}{ Возраст } \\
\cline { 2 - 4 } & Женщины & Мужчины & Bсе \\
\hline Объем выборки N & 251 & 321 & 572 \\
\hline Шкала 1. Переживание одиночества как негативного чувства & 0,01 & $0,19 * * *$ & $0,09 *$ \\
\hline Шкала 2. Отрицание переживания одиночества & 0,09 & $0,26^{* * *}$ & $0,18^{* *}$ \\
\hline $\begin{array}{l}\text { Шкала 3. Переживание одиночества как временного вынуж- } \\
\text { денного явления }\end{array}$ & $0,15^{*}$ & $0,23^{* * *}$ & $0,19 * *$ \\
\hline $\begin{array}{l}\text { Шкала 4. Одиночество как результат страха брать ответствен- } \\
\text { ность за других }\end{array}$ & 0,01 & $0,17 * *$ & $0,09 *$ \\
\hline $\begin{array}{l}\text { Шкала 5. Духовное одиночество как отсутствие поддержки, } \\
\text { понимания }\end{array}$ & 0,00 & $0,24 * * *$ & $0,12^{* *}$ \\
\hline Шкала 6. Одиночество вследствие внешней непривлекательности & $-0,09$ & $0,13^{*}$ & 0,02 \\
\hline Общий показатель & 0,05 & $0,26^{* * *}$ & $0,16^{* *}$ \\
\hline Субъективное ощущение одиночества & 0,05 & $0,20^{* * *}$ & $0,12^{* *}$ \\
\hline
\end{tabular}

$*-\mathrm{p}<0,05 ; * *-\mathrm{p}<0,01 ; * * *-\mathrm{p}<0,01$.

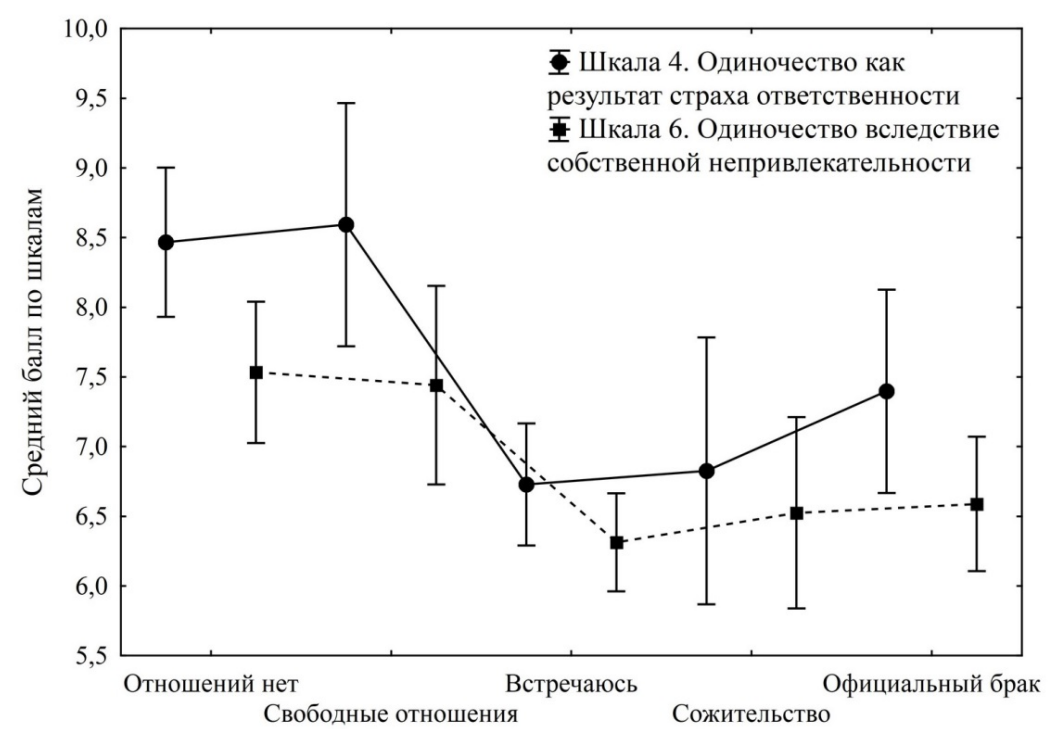

Тип отношений

Рис. 2. Особенности переживания одиночества в группах с различным типом

близких отношений по шкалам «Одиночество как результат страха брать ответственность» и «Одиночество вследствие внешней непривлекательности»

Субъективное ощущение одиночества и связанные с ним переживания могут зависеть от наличия или отсутствия близких отношений. Резуль- 
таты однофакторного дисперсионного анализа показали, что наличие и тип отношений, в которых состоят испытуемые, не оказывает существенного влияния на субъективное ощущение одиночества по шкале Д. Рассела и М. Фергюсона $(\mathrm{F}(4,551)=1,67, \mathrm{p}-$ незначим $)$. Большинство шкал предложенного опросника переживания одиночества также не показали зависимости от типа отношений, за исключением шкалы «Одиночество как результат страха брать ответственность» и «Одиночество вследствие внешней непривлекательности». В наглядной форме связь типа отношений с показателями по этим шкалам представлена на рис. 2.

Переживание одиночества как результат страха брать ответственность значительно более выражено у лиц, не состоящих в отношениях, либо состоящих в свободных отношениях $(\mathrm{F}(4,551)=7,47 ; \mathrm{p}<0,001)$. Для этих же лиц более характерно переживание одиночества вследствие собственной непривлекательности $(\mathrm{F}(4,551)=4,60 ; \mathrm{p}=0,01)$. Поскольку распределение мужчин и женщин по разным типам отношений довольно существенно различалось (см. табл. 1), для уточнения полученных результатов была проверена гипотеза о взаимодействии фактора типа отношений с фактором пола.

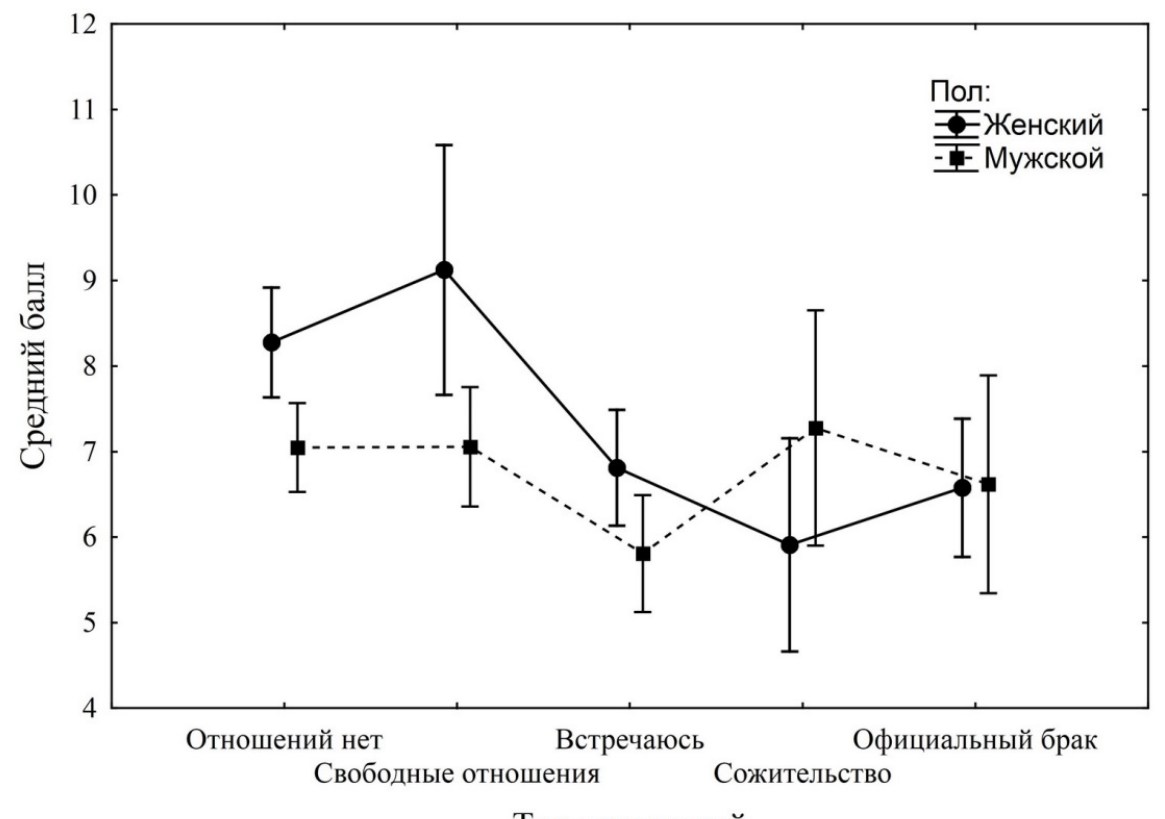

Тип отношений

Рис. 3. Особенности переживания одиночества по шкале «Одиночество вследствие внешней непривлекательности» в группах мужчин и женщин

Результаты двухфакторного дисперсионного анализа показали, что эффект взаимодействия типа отношений с полом не является статистиче- 
ски значимым для шкалы «Одиночество как результат страха брать ответственность». Следовательно, тенденция приписывать причины своего одиночества страху ответственности при отсутствии серьезных отношений одинаково характерна как для мужчин, так и для женщин. Вместе с тем был обнаружен статистически значимый эффект взаимодействия факторов типа отношений и пола на показатели по шкале «Одиночество вследствие внешней непривлекательности» $(\mathrm{F}(4,546)=2,49, \mathrm{p}<0,05)$. Этот эффект проявляется, как видно из рис. 3, в том, женщинам более свойственно связывать причины своего одиночества с собственной непривлекательностью в случае отсутствия отношений или наличия свободных отношений, в то время как у мужчин подобной тенденции не отмечается. Этот факт, очевидно, отражает большую субъективную значимость привлекательности как фактора установления отношений у женщин.

\section{Обсуждение результатов}

На основе результатов предшествующих исследований и теоретического анализа проблемы было определено шесть типов переживания одиночества, положенных в основу теоретической структуры предложенного опросника. Результаты эмпирического исследования показали, что теоретическая структура хорошо подтверждается в ходе конфирматорного факторного анализа, при этом все шкалы показывают отличную внутреннюю согласованность. Несмотря на тесные взаимосвязи между шкалами, их отношения с другими психологическими переменными (такими как стиль привязанности, субъективное благополучие и безнадежность) и социальнодемографическими характеристиками различаются довольно существенно, что свидетельствует об оправданности разведения этих аспектов переживания одиночества.

Результаты исследования позволяют сделать вывод о том, что различные типы переживания одиночества в разной мере влияют на психологическое благополучие. В частности, переживание одиночества как временного вынужденного явления наносит наименьший ущерб психологическому благополучию и не провоцирует состояния безнадежности. Следовательно, такой вариант переживания одиночества является наиболее конструктивным. В то же время переживания одиночества как негативного состояния или состояния, связанного с отсутствием понимания и поддержки довольно сильно снижают благополучие личности и способствуют возникновению безнадежности, повышающей риск суицидального поведения. Эти выводы представляют интерес в контексте психологического консультирования, позволяя наметить пути для формирования навыков конструктивного совладания с проблемой одиночества.

Интерес представляет тот факт, что в данном исследовании, в отличие от некоторых предыдущих [12], не удалось выявить связи субъективного ощущения одиночества с наличием близких отношений и их типом. Вероятно, этот факт объясняется преобладанием в составе выборки сту- 
денческой молодежи: в данном возрастном периоде отсутствие стабильных близких отношений может быть скомпенсировано обширностью контактов со сверстниками, многие из которых еще не обременены семьей и могут уделять много времени дружескому общению. В то же время результаты анализа по шкалам нового опросника продемонстрировали наличие особенностей переживания одиночества у лиц, состоящих в отношениях разного типа. В частности, юноши и девушки, не состоящие в серьезных отношениях, более склонны связывать причины своего одиночества со страхом принимать на себя ответственность. Кроме того, девушкам, не имеющим серьезных отношений, более свойственно рассматривать в числе причин собственную внешнюю непривлекательность. Следовательно, несмотря на отсутствие различий в уровне одиночества между теми, кто состоит в серьезных близких отношениях, и теми, кто в них не состоит, имеются явные отличия в том, как люди интерпретируют причины одиночества. Очевидно, что при отсутствии отношений такие причины чаще обнаруживаются в самом себе - в страхе ответственности и в собственной внешней непривлекательности (у девушек).

Полученные результаты убеждают в том, что предложенный опросник дает возможность углубленного анализа связанных с одиночеством переживаний, позволяя охарактеризовать представления о его причинах и определить выраженность вызванных им негативных эмоций. Структура опросника не дублирует состав других методик для диагностики субъективного ощущения одиночества и связанных с ним переживаний $[3,11$ и др.], предоставляя возможность измерения новых, прежде не рассмотренных, но представляющих существенный интерес аспектов переживания одиночества. Это позволяет надеяться, что предложенная методика будет востребована как в деятельности практических психологов, так и в дальнейших научных исследованиях проблемы одиночества. 


\section{Опросник переживания одиночества, инструкция и ключ к нему}

Приложение

Инструкция. Внимательно прочитайте каждое утверждение и оцените, в какой степени оно справедливо применительно к Вам. Просим Вас оценить каждое утверждение по пятибалльной шкале следующим образом: почти никогда - 1, редко - 2, время от времени - 3, часто - 4, почти всегда - 5 .

\begin{tabular}{|c|c|c|c|c|c|c|}
\hline $\begin{array}{l}\text { № } \\
\Pi / \Pi\end{array}$ & Утверждение & $\begin{array}{l}\text { Почти } \\
\text { нико- } \\
\text { гда }\end{array}$ & Редко & $\begin{array}{l}\text { Время } \\
\text { от } \\
\text { време- } \\
\text { ни } \\
\end{array}$ & Часто & $\begin{array}{l}\text { Почти } \\
\text { всегда }\end{array}$ \\
\hline 1 & $\begin{array}{l}\text { Когда я одинок(а), мне кажется, что жизнь } \\
\text { проходит мимо }\end{array}$ & & & & & \\
\hline 2 & $\begin{array}{l}\text { Одиночество - самое комфортное для } \\
\text { меня состояние }\end{array}$ & & & & & \\
\hline 3 & $\begin{array}{l}\text { Временное одиночество помогает мне } \\
\text { разобраться в себе, в своих чувствах и } \\
\text { отношениях с собой и с другими }\end{array}$ & & & & & \\
\hline 4 & $\begin{array}{l}\text { Проще быть одному, чем постоянно забо- } \\
\text { титься и беспокоиться о ком-то }\end{array}$ & & & & & \\
\hline 5 & $\begin{array}{l}\text { Мне одиноко оттого, что я не чувствую } \\
\text { поддержку в своих начинаниях }\end{array}$ & & & & & \\
\hline 6 & $\begin{array}{l}\text { Причина моего одиночества в том, что } \\
\text { многие считают меня непривлекатель- } \\
\text { ной(ым) }\end{array}$ & & & & & \\
\hline 7 & $\begin{array}{l}\text { Чувство одиночества пробуждает у меня } \\
\text { жалость к себе }\end{array}$ & & & & & \\
\hline 8 & $\begin{array}{l}\text { Я не нуждаюсь в общении, мне комфорт- } \\
\text { нее быть одному }\end{array}$ & & & & & \\
\hline 9 & $\begin{array}{l}\text { Переживая одиночество временами, я } \\
\text { научился(лась) с ним мириться }\end{array}$ & & & & & \\
\hline 10 & $\begin{array}{l}\text { Мне удобнее быть одному (одной), чем } \\
\text { выстраивать серьезные отношения с дру- } \\
\text { гим человеком }\end{array}$ & & & & & \\
\hline 11 & $\begin{array}{l}\text { Я чувствую одиночество, так как мое } \\
\text { мнение всегда остается неуслышанным } \\
\end{array}$ & & & & & \\
\hline 12 & $\begin{array}{l}\text { Если бы я был(а) так же привлекателен(а), } \\
\text { как и большинство других людей, то я не } \\
\text { страдал(а) бы от одиночества }\end{array}$ & & & & & \\
\hline 13 & $\begin{array}{l}\text { От своего одиночества мне часто хочется } \\
\text { плакать }\end{array}$ & & & & & \\
\hline 14 & $\begin{array}{l}\text { Я люблю проводить время в одиночестве } \\
\text { и никогда не хожу в гости }\end{array}$ & & & & & \\
\hline 15 & $\begin{array}{l}\text { В период одиночества я много читаю пси- } \\
\text { хологической литературы, слушаю музы- } \\
\text { ку, интересуюсь искусством. }\end{array}$ & & & & & \\
\hline 16 & $\begin{array}{l}\text { Страх ответственности мешает мне уста- } \\
\text { навливать близкие отношения с другими } \\
\text { людьми }\end{array}$ & & & & & \\
\hline 17 & $\begin{array}{l}\text { Мне одиноко оттого, что многие окружа- } \\
\text { ющие люди слишком инфантильны, и мне } \\
\text { не с кем поделиться чем-то важным }\end{array}$ & & & & & \\
\hline
\end{tabular}




\begin{tabular}{|c|c|c|c|c|c|c|}
\hline $\begin{array}{l}\text { № } \\
\Pi / \Pi\end{array}$ & Утверждение & $\begin{array}{l}\text { Почти } \\
\text { нико- } \\
\text { гда }\end{array}$ & Редко & $\begin{array}{c}\text { Время } \\
\text { от } \\
\text { време- } \\
\text { ни }\end{array}$ & Часто & $\begin{array}{l}\text { Почти } \\
\text { всегда }\end{array}$ \\
\hline 18 & $\begin{array}{l}\text { Уверен(а), что внешняя непривлекатель- } \\
\text { ность - одна из главных причин одиноче- } \\
\text { ства }\end{array}$ & & & & & \\
\hline 19 & $\begin{array}{l}\text { В одиночестве я испытываю внутреннюю } \\
\text { борьбу с чувством опустошенности }\end{array}$ & & & & & \\
\hline 20 & $\begin{array}{l}\text { Предпочитаю всегда гулять по улице в } \\
\text { одиночестве }\end{array}$ & & & & & \\
\hline 21 & $\begin{array}{l}\text { Я уверен(a), что период одиночества вы- } \\
\text { ведет меня на новый этап жизни }\end{array}$ & & & & & \\
\hline 22 & $\begin{array}{l}\text { Я предпочитаю одиночество, так как мне } \\
\text { не хочется прикладывать усилия для } \\
\text { установления и поддержания серьезных } \\
\text { отношений } \\
\end{array}$ & & & & & \\
\hline 23 & $\begin{array}{l}\text { Я часто чувствую свое одиночество отто- } \\
\text { го, что никто не понимает меня }\end{array}$ & & & & & \\
\hline 24 & $\begin{array}{l}\text { Мне одиноко, так как из-за своей непри- } \\
\text { влекательности мне не удается... }\end{array}$ & & & & & \\
\hline 25 & $\begin{array}{l}\text { Когда я одинок(а), я ощущаю свою } \\
\text { ненужность }\end{array}$ & & & & & \\
\hline 26 & Люблю проводить досуг в одиночестве & & & & & \\
\hline 27 & $\begin{array}{l}\text { Одиночество стараюсь рассматривать для } \\
\text { себя как ресурс саморазвития, несмотря } \\
\text { на дискомфорт }\end{array}$ & & & & & \\
\hline 28 & $\begin{array}{l}\text { Я лучше буду один, чем тратить время и } \\
\text { силы на хлопотность совместного прожи- } \\
\text { вания с кем-либо }\end{array}$ & & & & & \\
\hline 29 & $\begin{array}{l}\text { Мои идеи не воспринимаются серьезно и } \\
\text { не поддерживаются окружающими, по- } \\
\text { этому мне одиноко }\end{array}$ & & & & & \\
\hline 30 & $\begin{array}{l}\text { Мне очень одиноко, так как из-за моей } \\
\text { непривлекательности многие даже не } \\
\text { пытаются узнать меня по-настоящему }\end{array}$ & & & & & \\
\hline
\end{tabular}

Ключ

\begin{tabular}{|l|c|}
\hline \multicolumn{1}{|c|}{ Шкалы } & \multicolumn{1}{|c|}{$\begin{array}{c}\text { Номера } \\
\text { утверждений }\end{array}$} \\
\hline Шкала 1. Переживание одиночества как негативного чувства & 17131925 \\
\hline Шкала 2. Отрицание переживания одиночества & 28142026 \\
\hline $\begin{array}{l}\text { Шкала 3. Переживание одиночества как временного вынужден- } \\
\text { ного явления }\end{array}$ & 39152127 \\
\hline $\begin{array}{l}\text { Шкала 4. Одиночество как результат страха брать ответствен- } \\
\text { ность за других }\end{array}$ & 410162228 \\
\hline $\begin{array}{l}\text { Шкала 5. Духовное одиночество как отсутствие поддержки, по- } \\
\text { нимания }\end{array}$ & 511172329 \\
\hline $\begin{array}{l}\text { Шкала 6. Физическое одиночество вследствие собственной не- } \\
\text { привлекательности }\end{array}$ & 612182430 \\
\hline
\end{tabular}

Все утверждения прямые, так что итоговый балл получается суммированием оценок по утверждениям, входящим в шкалу. 


\section{Лumepamypa}

1. Статистика ВЦИОМ: любовь или одиночество - чего больше в жизни россиян? URL: http://scisne.net/a-2126 (дата обращения: 11.04.2017).

2. Эриксон Э. Идентичность: юность и кризис. Идентичность. М. : Прогресс, 1996. 340 с.

3. Ишмухаметов И.Н. Психометрические характеристики шкалы одиночества UCLA (версия 3): изучение студентов вуза // Computer Modelling and New Technologies. 2006. T. 10, № 3. C. 89-95.

4. Mikulincer M., Shaver P.R. An Attachment Perspective on Loneliness // The Handbook of Solitude / eds. R.J. Coplan, J.C. Bowker. John Wiley \& Sons, 2014. P. 34-50.

5. Berlin L.J., Cassidy J., Belsky J. Loneliness in Young Children and Infant-Mother Attachment: A Longitudinal Study // Merrill-Palmer Quarterly. 1995. Vol. 41 (1). P. 91-103.

6. Givertz M., Woszidlo A., Segrin C., Knutson K. Direct and indirect effects of attachment orientation on rela-tionship quality and loneliness in married couples // Journal of Social and Personal Relationships. 2013. Vol. 30 (8). P. 1096-1120.

7. Крюкова Т.Л. Психология совладания с одиночеством // Психологические исследования. 2016. Т. 9, № 49. С. 1.

8. Cacioppo J.T., Patrick W. Loneliness: Human nature and the need for social connection. WW Norton \& Company, 2008. 336 p.

9. Handbook of Social Support and the Family. Boston, MA : Springer US, 1996. 574 p.

10. Майерс Д. Социальная психология : интенсивный курс. СПб. : Прайм-Еврознак, 2007. $510 \mathrm{c}$.

11. Осин Е.Н., Леонтьев Д.А. Дифференциальный опросник переживания одиночества: структура и свойства // Психология. Журнал Высшей школы экономики. 2013. T. 10, № 1. C. 55-81.

12. Andersson L. Loneliness research and interventions: a review of the literature // Aging \& Mental Health. 1998. Vol. 2 (4). P. 264-274.

13. Perlman D., Russell D. Loneliness and health // Encyclopedia of health \& behavior / ed. N.B. Andeson. 2004. Vol. 2. P. 585-589.

14. Tiikkainen P., Heikkinen R.-L., Leskinen E. The structure and stability of perceived togetherness in elderly people during a 5-year follow-up // Journal of Applied Gerontology. 2004. Vol. 23 (3). P. 279-294.

15. Слободчиков И.М. Теоретико-экспериментальное исследование феномена одиночества личности: (на материале подросткового возраста) : дис. ... д-ра психол. наук. M., 2006. 330 c.

16. Kupersmidt J.B., Sigda K.B., Sedikides C., Voegler M.E. Social self-discrepancy theory and loneliness during childhood and adolescence // Loneliness in childhood and adolescence / eds. K. Rotenberg, S. Hymel. 1999. P. 263-279.

17. Василюк Ф.Е. Психология переживания: анализ преодоления критических ситуаций. М. : Изд-во МГУ, 1984. 200 с.

18. Манакова Е.А. Типы переживания одиночества в контексте психологического здоровья девушек-студенток : дис. ... канд. психол. наук. М., 2015. 204 с.

19. Черепухин Ю.М. Семейные установки одиноких мужчин // Социологический журнал. 1995. № 1. С. 159-165.

20. Красникова О.М. Одиночество. М. : Никея, 2015. 203 с.

21. Соколова М.В. Шкала субъективного благополучия. Ярославль : НПЦ «Психодиагностика», 1996. 13 с.

22. Beck A.T., Weissman A., Lester D., Trexler L. The measurement of pessimism: the hopelessness scale // Journal of Consulting and Clinical Psychology. 1974. Vol. 42 (6). P. 861865.

23. Beck A.T., Steer R.A., Kovacs M., Garrison B. Hopelessness and eventual suicide: a 10year prospective study of patients hospitalized with suicidal ideation // The American Journal of Psychiatry. 1985. Vol. 142 (5). P. 559-563. DOI: 10,1176/ajp.142,5.559. 
24. Сабельникова Н.В., Каширский Д.В. Опросник привязанности к близким людям // Психологический журнал. 2015. Т. 36, № 4. С. 84-97.

25. Brennan K.A., Clark C.L., Shaver P.R. Self-report measurement of adult attachment: an integrative overview // Attachment theory and close relationships / eds. J.A. Simpson, W.S. Rholes. New York : Guilford Press, 1998. P. 46-76.

26. Сагалакова О.А., Труевцев Д.В. Опросник социальной тревоги и социофобии // Медицинская психология в России. 2012. № 4 (15). URL: http://medpsy.ru (дата обращения: 13.03.2017).

Поступила в редакиию 17.03.2018 г.; принята 31.05.2018 г.

\section{Сведения об авторе:}

МАНАКОВА Екатерина Александровна, кандидат психологических наук, доцент кафедры психологии Алтайского государственного педагогического университета (Барнаул, Россия). E-mail: 25198787@mail.ru

\section{EXPERIENCE OF LONELINESS QUESTIONNAIRE}

Sibirskiy Psikhologicheskiy Zhurnal - Siberian journal of psychology, 2018, 69, 149-171. DOI: 10.17223/17267080/69/9

Ekaterina A. Manakova, Altay State Pedagogical University (Barnaul, Russian Federation). E-mail: 25198787@mail.ru

Keywords: experience of loneliness; social phobia; attachment styles; subjective well-being.

The article represents the results of elaborating the method of loneliness experience diagnostics. On the basis of theoretical analysis and literature review we identified five types of loneliness experience: "Experience of loneliness as a negative feeling", "Denial the experience of loneliness", "Experience of loneliness as a temporary forced condition", "Loneliness as a result of fear to take responsibility", "Spiritual loneliness as absence of support and understanding", "Loneliness as a result of unattractiveness". For measuring these types of experience of loneliness we designed the questionnaire of 30 statements. It was probed in the sample of 572 (preliminary university students) participants, single or in different types of relationship. The results of confirmatory factor analysis affirmed the theoretical structure of the questionnaire, all the scales showed excellent internal consistency (Cronbach's alpha 0.760.84). Convergent validity of scales was confirmed by high correlations with UCLA Loneliness Scale ( $\mathrm{r}$ from 0.43 to 0.61 for different scales). Construct validity of scales was confirmed by expected correlations with subjective well-being, hopelessness, attachment styles and social phobia. Substantive influence on experience of loneliness showed factors of gender, age and types of relationships. Women demonstrated higher mean scores by all the scales of experience of loneliness except one ("Loneliness as a result of fear to take responsibility"). The influence of age and types of relationships on experience of loneliness differs in men and women. The proposed questionnaire open perspectives for measuring new interesting aspects of experience of loneliness and it may be recommended for investigations and consulting.

\section{References}

1. VTSIOM. (n.d.) Statistika VTSIOM: lyubov' ili odinochestvo - chego bol'she v zhizni rossiyan? [VTsIOM Statistics: love or loneliness - what the Russians have more?]. [Online] Available from: http://scisne.net/a-2126. (Accessed: 11th April 2017).

2. Erikson, E. (1996) Identichnost': yunost' $i$ krizis. Identichnost' [Identity: youth and crisis. Identity]. Translated from English. Moscow: Progress.

3. Ishmukhametov, I.N. (2006) Psikhometricheskie kharakteristiki shkaly odinochestva UCLA (versiya 3): izuchenie studentov vuza [Psychometric characteristics of the UCLA loneliness scale (version 3): a study of university students]. Computer Modelling and New Technologies. 10(3). pp. 89-95. 
4. Mikulincer, M. \& Shaver, P.R. (2014) An Attachment Perspective on Loneliness. In: Coplan, R.J. \& Bowker, J.C. (eds) The Handbook of Solitude. John Wiley \& Sons. pp. $34-50$.

5. Berlin, L.J., Cassidy, J. \& Belsky, J. (1995) Loneliness in Young Children and InfantMother Attachment: A Longitudinal Study. Merrill-Palmer Quarterly. 41(1). pp. 91-103.

6. Givertz, M., Woszidlo, A., Segrin, C. \& Knutson, K. (2013) Direct and indirect effects of attachment orientation on relationship quality and loneliness in married couples. Journal of Social and Personal Relationships. 30(8). pp. 1096-1120. DOI: $10.1177 / 0265407513482445$

7. Kryukova, T.L. (2016) Coping with loneliness psychology. Psikhologicheskie issledovaniya. 9(49). pp. 1. (In Russian).

8. Cacioppo, J.T. \& Patrick, W. (2008) Loneliness: Human nature and the need for social connection. WW Norton \& Company.

9. Pierce, G.R. \& Sarason, I.G. (eds) Handbook of Social Support and the Family. Boston, MA: Springer US.

10. Mayers, D. (2007) Sotsial'naya psikhologiya: intensivnyy kurs [Exploring Social Psychology]. Translated from English by L. Tsaruk. St. Petersburg: Praym-Evroznak.

11. Osin, E.N. \& Leontiev, D.A. (2013) Multidimensional Inventory of Loneliness Experience: Structure and Properties. Psikhologiya. Zhurnal Vysshey shkoly ekonomiki - Psychology. Journal of the Higher School of Economics. 10(1). pp. 55-81. (In Russian).

12. Andersson, L. (1998) Loneliness research and interventions: a review of the literature. Aging \& Mental Health. 2(4). pp. 264-274. DOI: 10.1080/13607869856506

13. Perlman, D. \& Russell, D. (2004) Loneliness and health. In: Andeson, N.B. (ed.) Encyclopedia of Health \& Behavior. Vol. 2. Sage Publishing. pp. 585-589.

14. Tiikkainen, P., Heikkinen, R.-L. \& Leskinen, E. (2004) The structure and stability of perceived togetherness in elderly people during a 5-year follow-up. Journal of Applied Gerontology. 23(3). pp. 279-294. DOI: 10.1177/0733464804267582

15. Slobodchikov, I.M. (2006) Teoretiko-eksperimental'noe issledovanie fenomena odinochestva lichnosti: (na materiale podrostkovogo vozrasta) [Theoretical and experimental study of the phenomenon of individual solitude: (a case study of adolescence)]. Psychology Dr. Diss. Moscow.

16. Kupersmidt, J.B., Sigda, K.B., Sedikides, C. \& Voegler, M.E. (1999) Social selfdiscrepancy theory and loneliness during childhood and adolescence. In: Rotenberg, K. \& Hymel, S. (eds) Loneliness in childhood and adolescence. Cambridge University Press. pp. $263-279$.

17. Vasilyuk, F.E. (1984) Psikhologiya perezhivaniya: analiz preodoleniya kriticheskikh situatsiy [Psychology of experience: analysis of overcoming critical situations]. Moscow: Moscoe State University.

18. Manakova, E.A. (2015) Tipy perezhivaniya odinochestva $v$ kontekste psikhologicheskogo zdorov'ya devushek-studentok [Types of experiencing loneliness in the context of the psychological health of female students]. Psychology Cand. Diss. Moscow.

19. Cherepukhin, Yu.M. (1995) Semeynye ustanovki odinokikh muzhchin [Family installation of single men]. Sotsiologicheskiy zhurnal - Sociological Journal. 1. pp. 159-165.

20. Krasnikova, O.M. (2015) Odinochestvo [Loneliness]. Moscow: Nikeya.

21. Sokolova, M.V. (1996) Shkala sub"ektivnogo blagopoluchiya [Scale of subjective wellbeing]. Yaroslavl: Psikhodiagnostika.

22. Beck, A.T., Weissman, A., Lester, D. \& Trexler, L. (1974) The measurement of pessimism: the hopelessness scale. Journal of Consulting and Clinical Psychology. 42(6). pp. 861-865. DOI: $10.1037 / \mathrm{h} 0037562$

23. Beck, A.T., Steer, R.A., Kovacs, M. \& Garrison, B. (1985) Hopelessness and eventual suicide: a 10-year prospective study of patients hospitalized with suicidal ideation. The American Journal of Psychiatry. 142(5). pp. 559-563. DOI: 10,1176/ajp.142,5.559 
24. Sabelnikova, N.V. \& Kashirskiy, D.V. (2015) Oprosnik privyazannosti k blizkim lyudyam [The questionnaire of attachment to close people]. Psikhologicheskiy zhurnal. 36(4). pp. 84-97.

25. Brennan, K.A., Clark, C.L. \& Shaver, P.R. (1998) Self-report measurement of adult attachment: an integrative overview. In: Simpson, J.A. \& Rholes, W.S. (eds) Attachment theory and close relationships. New York: Guilford Press. pp. 46-76.

26. Sagalakova, O.A. \& Truevtsev, D.V. (2012) Oprosnik sotsial'noy trevogi i sotsiofobii [The questionnaire of social anxiety and social phobia]. Meditsinskaya psikhologiya $v$ Rossii. 4(15). [Online] Avaible from: http://medpsy.ru. (Accessed: 13th March 2017).

Received 17.03.2018; Accepted 31.05.2018 